(2) Open Access Full Text Article

\title{
Primary probing for congenital nasolacrimal duct obstruction with manually curved Bowman probes
}

This article was published in the following Dove Press journal:

Clinical Ophthalmology

10 January 2013

Number of times this article has been viewed

\author{
Didem Serin' \\ Ibrahim Bulent Buttanri' \\ Mehmet Sahin Sevim' \\ Bahtinur Buttanri \\ 'Eye Clinic, Haydarpasa Numune \\ Education and Research Hospital, \\ ${ }^{2}$ Eye Clinic, Sisli Etfal Education and \\ Research Hospital, Istanbul, Turkey
}

Correspondence: Ibrahim Bulent Buttanri Haydarpasa Egitim ve Arastırma Hastanesi Tibbiye, Caddesi No 40 Uskudar, Istanbul, Turkey

Tel +90532 3II 6673

Fax +90 2133377877

Email bulent_but@yahoo.com
Purpose: To evaluate the effect of the shape of Bowman probes on the success of primary probing for congenital nasolacrimal duct obstruction.

Materials and methods: Records of 42 nasolacrimal duct obstructions in 37 children who underwent probing with straight Bowman probes (group A) and 128 nasolacrimal duct obstructions in 110 children who underwent probing with Bowman probes manually bent to mimic the natural curve of the bony nasolacrimal pathway (group B) were evaluated and compared. All children were under 2 years of age. The main outcome was successful probing. Successful probing was defined as a complete resolution of signs and symptoms.

Results: The mean age of the patients was $16.4 \pm 4.1$ months (range 8-24 months) in group A and 16.8 \pm 4.2 months (range 7-24 months) in group B. No canalicular or nasolacrimal sac pathologies were diagnosed during probing. The success rate was $76.2 \%(32 / 42)$ in group A and $91.4 \%(117 / 128)$ in group B. The difference was statistically significant $(P<0.01)$.

Conclusion: Manually curved probes can be used efficiently during probing and increase the success rates.

Keywords: nasolacrimal duct obstruction, success rate, curved Bowman probe, $<2$-year-old children

\section{Introduction}

Congenital nasolacrimal duct obstruction (CNLDO) is a major problem of the nasolacrimal system in infancy and childhood. ${ }^{1}$ An embryological membrane obstructs the distal end of the nasolacrimal duct (NLD) in most cases, and patients present with epiphora and discharge. ${ }^{2}$ Most cases resolve spontaneously or with lacrimal massage in the first year of life. ${ }^{3,4}$ If the condition persists, most authors agree that NLD probing is the most effective treatment modality with high success rates in or around the first year of life. ${ }^{5}$ Surgical techniques and tools chosen by different surgeons during probing may affect the results of probing and have not yet been studied. Some surgeons use straight Bowman probes ${ }^{6}$ and some suggest curved Bowman probes to mimic the curve of the bony nasolacrimal pathway in children. ${ }^{7}$

The aim of this study was to evaluate the effect of the shape of Bowman probes on the success rate of initial probing for CNLDO in children $<2$ years of age.

\section{Material and methods}

The current study is a retrospective, interventional study. Group A comprised 42 CNLDOs in 37 children who underwent probing with straight Bowman probes (Katena Products, NJ, USA) and group B comprised 128 CNLDOs in 110 children 
who underwent probing with Bowman probes (size one) manually bent approximately 15 degrees to mimic the natural curve of the bony nasolacrimal pathway between January 2007 and March 2011. The diagnosis of CNLDO was based on a history of epiphora and discharge since the first months of life and delayed fluorescein disappearance time. A detailed ophthalmological examination was performed to eliminate any other ophthalmological problem which may cause epiphora such as congenital glaucoma, trichiasis, conjunctivitis, keratitis, and metabolic disorders. Patients $<2$ years of age were included in the study. Patients with congenital craniofacial and lid abnormalities, punctal agenesis, a history of trauma, nasolacrimal surgery, previous probing or other nasolacrimal intervention, and postoperative follow-up $<3$ months were excluded from the study.

Written informed consent was obtained from the patients' families preoperatively. The tenets of the Declaration of Helsinki were followed in the study. All patients underwent primary probing under general anesthesia. In group A, straight Bowman probes (Katena Products) were used; in group B, Bowman probes gently curved to mimic the bony nasolacrimal pathway were used (Figure 1). The surgeon dilated both puncta with a fine punctal dilator (Infant lacrimal dilator, Katena Products). The probe was inserted through the upper punctum into the ampulla of the upper canaliculus and then rotated horizontally to fit in the canaliculus. Lateral traction was applied to the eyelid to prevent kink formation. After a "hard stop" was felt, the probe was slightly retracted and rotated 90 degrees. At this point, in group A, the straight Bowman probe was directly advanced toward the NLD; in group B, the curve of the probe was turned posteriorly and medially while advancing toward the NLD. ${ }^{7}$ After a popping sensation was felt, passage into the nose was confirmed by metal-to-metal contact under the inferior turbinate with another probe. The same procedure was repeated from the lower punctum to exclude any lower canalicular obstruction. After the operation, all patients received a topical steroid

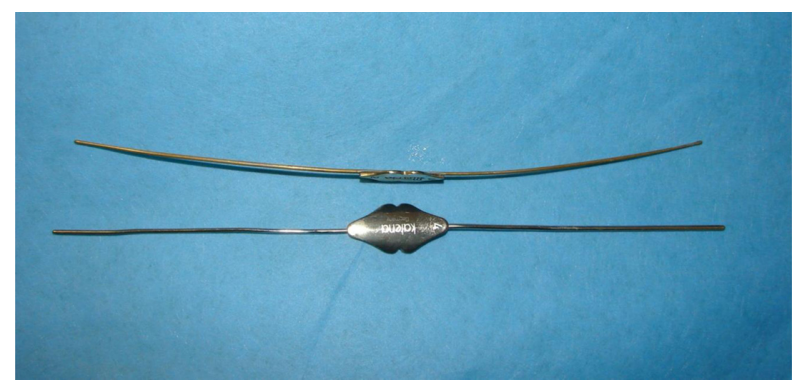

Figure I Manually bent Bowman probes to mimic the natural curve of the nasolacrimal duct in children. and antibiotic treatment four times daily for 10 days and a nasal decongestant for 5 days. The patients were evaluated at 1 week, 1 month, and 3 months. A fluorescein disappearance test was repeated at 3 months. Successful probing was defined as a complete resolution of signs and symptoms at 3 months postoperatively. The chi-squared test was used for the comparison of success rates. $P<0.05$ was considered statistically significant.

\section{Results}

The mean age of the patients was $16.4 \pm 4.1$ months (range 8-24 months) in group A and 16.8 \pm 4.2 months (range 7-24 months) in group B. Both groups were similar regarding age characteristics. No canalicular or nasolacrimal sac pathologies were diagnosed during probing. The success rate was 76.2\% (32/42) in group A and 91.4\% (117/128) in group B. The difference was statistically significant $(P<0.01)$.

\section{Discussion}

NLD probing is an effective therapeutic procedure in the management of CNLDO; however, different success rates were reported in the same age groups by different authors. Limbu et al reported a success rate of $90.2 \%$ in a group of children $<2$ years of age; ${ }^{8}$ however, Repka et al reported a success rate of $78 \%$ in children $6-12$ months of age and $79 \%$ in children 12-24 months of age. ${ }^{9}$ In children $>2$ years of age, success rates of probing is much more controversial. Robb reported that the success rate of probing was $94.5 \%$ in patients aged $\geq 2$ years. ${ }^{10}$ In contrast, in Sturrock et al's study the success rate was $42 \%$ in patients probed after 2 years of age and Young et al reported a cure rate of $54 \%$ in the same age group. ${ }^{11,12}$ The reason for the different success rates reported previously is unclear. Some authors performed simple NLD probing and some combined probing with inferior turbinate fracture. ${ }^{11,13}$ Nasal endoscopy was also used in some studies. ${ }^{6}, 14$ Patient characteristics may affect the surgical results of probing. ${ }^{15}$ Additionally, the anatomy of NLD, surgical techniques, and tools chosen by different surgeons during probing may affect the results of probing and have not yet been studied.

In children, the NLD slopes downwards medially and posteriorly. ${ }^{7}$ Some surgeons use straight Bowman probes and some suggest gentle recontouring of the probe to suit the configuration of the bony nasolacrimal pathway in children; ${ }^{6,7}$ however, no comparative studies have been conducted yet. In this study, probing with manually curved Bowman probes was performed in 110 children and the results compared with those performed by the same surgeons with straight probes before October 2008. 
For effective probing, an ophthalmologist must pass the probe through the bony nasolacrimal canal and perforate the embryological membrane without traumatizing other anatomical structures or creating a false passage. In the current study, a complete resolution of signs and symptoms was achieved in $76.2 \%$ of eyes with a straight Bowman probe and in $91.4 \%$ of eyes with a curved Bowman probe and the difference was statistically significant $(P<0.01)$. In children, the slope of the NLD may make it difficult to pass a straight Bowman probe through the NLD without trauma. Strenuous attempts to pass a straight Bowman probe through a curved NLD may cause mucosal damage, submucosal passage, and synechia formation in the duct. In group B, the Bowman probe was gently bent to mimic the curve of the bony nasolacrimal pathway, as suggested by Robb. ${ }^{7}$ This may lead to an easy introduction of the probe into the duct, and advancement through the duct without rubbing and traumatizing the mucosa or the bony structures of the canal may be possible and this may be the reason of the high success rate of probing with recontoured probes.

Some authors classify CNLDO into two main groups membranous and complex (firm) - based on the sensation while passing the Bowman probe. ${ }^{16}$ If the passage of the probe produces a popping sensation with subsequent free passage, it is called a membranous obstruction and if the passage of the probe produces a bony sensation similar to passing the probe through sandpaper, it is called a complex (firm) obstruction. However, this classification is subjective and depends on the feeling during probing and different rates of obstruction types were reported in the same age groups by different authors. ${ }^{17,18}$ The medially and posteriorly directed NLD can make it difficult to pass a straight Bowman probe through the NLD in children. Therefore, it may be a misdirected Bowman probe that produces the bony sensation, which might result in a membranous obstruction being misdiagnosed as a firm or complex obstruction. This may be one of the reasons for the controversy that exists regarding the rates of obstruction types and the outcomes in different studies. With a curved Bowman probe, the probability of misdirection and false passage formation may be reduced and success rates of probing may be increased.

\section{Conclusion}

According to the results, using a curved Bowman probe in children with CNLDO is more effective in the management of CLNDO than a straight probe. Curved probes that mimic the slope of the NLD can be used efficiently during probing. Production and usage of tools that mimic the NLD anatomy also for silicone intubation or balloon dacryocystoplasty may be taken into consideration for possible higher success rates. Anatomical studies of the nasolacrimal system in children are required to further evaluate the effectiveness of surgical techniques and tools used for the management of CLNDO.

\section{Disclosure}

The authors report no conflicts of interest in this work.

\section{References}

1. Guerry D 3rd, Kendig EL Jr. Congenital impotency of the nasolacrimal duct. Arch Ophthalmol. 1948;39:193-204.

2. Kashkouli MB, Beigi B, Parvaresh MM, Kassaee A, Tabatabaee Z. Late and very late initial probing for congenital nasolacrimal duct obstruction: what is the cause of failure? Br J Ophthalmol. 2003;87(9): 1151-1153.

3. Pediatric Eye Disease Investigator Group. Resolution of congenital nasolacrimal duct obstruction with nonsurgical management. Arch Ophthalmol. 2012;130(6):730-734.

4. Nucci P, Capoferri C, Alfarano R, Brancato R. Conservative management of congenital nasolacrimal duct obstruction. J Pediatr Ophthalmol Strabismus. 1989;26(1):39-43.

5. Katowitz JA, Welsh MG. Timing of initial probing and irrigation in congenital nasolacrimal duct obstruction. Ophthalmology. 1987;94(6): 698-705.

6. Kouri AS, Tsakanikos M, Linardos E, Nikolaidou G, Psarommatis I. Results of endoscopic assisted probing for congenital nasolacrimal duct obstruction in older children. Int J Pediatr Otorhinolaryngol. 2008;72(6):891-896.

7. Robb RM. Pediatric lacrimal surgery. In: Albert DM, editor. Ophthalmic Surgery: Principles and Techniques. Hoboken, NJ: Wiley-Blackwell; 1999:1015-1023.

8. Limbu B, Akin M, Saiju R. Age-based comparison of successful probing in Nepalese children with nasolacrimal duct obstruction. Orbit. 2010;29(1):16-20.

9. Repka MX, Chandler DL, Beck RW, et al. Primary treatment of nasolacrimal duct obstruction with probing in children younger than 4 years. Ophthalmology. 2008;115(3):577-584.

10. Robb RM. Success rate of nasolacrimal duct probing at time intervals after 1 year of age. Ophthalmology. 1998;105(7):1307-1309.

11. Sturrock SM, MacEwan CJ, Young JD. Long-term results after probing for congenital nasolacrimal duct obstruction. Br JOphthalmol. 1994;78(12):892-894.

12. Young JD, MacEwan CJ, Ogstan SA. Congenital nasolacrimal duct obstruction in second year of life: a multicenter trial of management. Eye (Lond). 1996;10(Pt 4):485-491.

13. Havins HE, Wilkins RB. A useful alternative to slicone intubation in congenital nasolacrimal duct obstructions. Ophthalmic Surg. 1983;14(8):660-670.

14. Elmorsy S, Shabana YK, Fayek HM. Endoscopic assisted probing for symptomatic congenital nasolacrimal ductablet obstruction after one year of age. Rhinology. 2010;48(1):100-103.

15. Al-Faky YH, Al-Sobaie N, Mousa A, et al. Evaluation of treatment modalities and prognostic factors in children with congenital nasolacrimal ductobstruction. J AAPOS. 2012;16(1):53-57.

16. Maheshwari R, Maheshawri S. Late probing for congenital nasolacrimal duct obstruction. J Coll Physicians Surg Pak. 2007;17(1):41-43.

17. Chen PL, Hsiao CH. Balloon dacryocystoplasty as the primary treatment in older children with congenital nasolacrimal duct obstruction. JAAPOS. 2005;9(6):546-549.

18. Maheshwari R. Success rate and cause of failure for late probing for congenital nasolacrimal duct obstruction. J Pediatr Ophthalmol Strabismus. 2008;45(3):168-171. 


\section{Publish your work in this journal}

Clinical Ophthalmology is an international, peer-reviewed journal covering all subspecialties within ophthalmology. Key topics include: Optometry; Visual science; Pharmacology and drug therapy in eye diseases; Basic Sciences; Primary and Secondary eye care; Patient Safety and Quality of Care Improvements. This journal is indexed on

Submit your manuscript here: http://www.dovepress.com/clinical-ophthalmology-journal
PubMed Central and CAS, and is the official journal of The Society of Clinical Ophthalmology (SCO). The manuscript management system is completely online and includes a very quick and fair peer-review system, which is all easy to use. Visit http://www.dovepress.com/ testimonials.php to read real quotes from published authors. 